magazine articles, visits to zoos and museums — and even through hobbies such as gardening and birdwatching. This process of 'informal science education' is patchy, ad hoc and at the mercy of individual whim, all of which makes it much more difficult to measure than formal instruction. But it is also pervasive, cumulative and often much more effective at getting people excited about science - and an individual's realization that he or she can work things out unaided promotes a profoundly motivating sense of empowerment.

This suggests that policy-makers who focus exclusively on the classroom are missing an opportunity: even modest investment in informal science education could help to make the very large investment in formal instruction considerably more effective. Most of the necessary infrastructure is already in place: museums and zoos, for example, have been around for generations. Likewise, government funding mechanisms - agencies such as NASA and the National Science Foundation (NSF) have been funding science exhibits, television specials

"The personal nature of informal science education is what makes it powerful. The question 'why is this relevant?' never even arises." and other informal science-education projects for many years.

More recently, the NSF has begun supporting systematic research into how people learn in informal settings. The first attempt to integrate the findings from this research and to draw broad lessons from it was reported in a study released by the National Academies in January 2009. This was followed, last month, by a companion volume that focused on the most effective ways to apply those lessons. Since 2007, the NSF has also funded the not-for-profit Center for Advancement of Informal Science Education in Washington DC to coordinate efforts across the entire field - from film and broadcast media to botanical gardens to digital gaming.

Despite the obvious pitfalls of self-guided learning — starting with the huge amount of superficially plausible misinformation and pseudoscience available through sources such as the Internet and creationist museums - researchers have found that people are generally adept at picking up and applying information on subjects that matter to them. Someone with gallstones, for example, may well be able to discourse at length about the gall bladder; many small-town residents have no trouble figuring out why local fishing improved after a paper mill closed; and a ten-year-old who gets a pet snake is likely to end up knowing more than most about herpetology.

Indeed, researchers say, the personal and idiosyncratic nature of informal science education is precisely what makes it powerful. The question that plagues classroom science - why is this relevant? - never even arises. And, because it is not tied to school, informal learning is equally available to adults - many of whom find themselves confronting issues surrounding genetically modified crops or Internet privacy that didn't exist when they were students. If they are going to learn about these issues at all, most will have to do so outside the classroom.

There is, however, still much that researchers don't understand about informal science learning. It seems to be cumulative, but how do people integrate the disparate pieces of knowledge they acquired at different times and places? And how can anyone assess the overall outcome? In addition to measuring cognitive factors such as vocabulary gain or the ability to apply a formula, informal learning needs metrics for affective qualities such as attitudes, interests and behaviours. How well have people learned to think on their feet, for example? And how good are they at weighing-up evidence and asking critical questions?

The NSF, to its credit, is funding research into this area, and many others relating to informal learning. It should continue to do so. In the meantime, however, education authorities need to recognize the importance of informal science education and do more to promote it - if only as a way to motivate students in the classroom.

There are encouraging signs that this is beginning to happen. Since 2004, for example, the California Science Center in Los Angeles has operated an elementary school on its grounds, and the museum and its resources are integrated into the school's curriculum. In both the United States and the United Kingdom, dozens of museums and zoos are exploring variations on this theme as they build relationships with nearby schools. In addition, some research initiatives have begun building in citizen-science components. A prime example is the education component of the NSF's nascent National Ecological Observatory Network, which hopes to recruit large groups of citizenscience volunteers to monitor invasive species, the effects of climate change and other environmental issues.

Such experiments should be encouraged and expanded. Striking the right balance between formal and informal science education will never be easy, but the answer is not to focus exclusively on the small fraction of people's lives spent in school. Policy-makers need to start looking at alternative models.

\section{Attention Canadian mentors}

S ince they were launched in 2005, Nature's awards for mentoring in science have rewarded outstanding research mentors in Britain, Germany, Japan, Australia and South Africa. The competition is held within one country each year, in the belief that mentoring reflects not just notions of good scientific practice and creativity that are universal, but also scientific traditions and cultures that are, at least to a degree, national. (For details of past competitions, see go.nature.com/Rccbo4. For our guide to outstanding mentoring, see Nature 447, 791-797; 2007.)

This year's competition is taking place in Canada. Two prizes of Can $\$ 10,000$ (US $\$ 9,900$ ) will be awarded, one for a mid-career mentor and one for lifetime achievement in mentoring.

Nominations are now open, with a closing date of 30 June 2010. The prizes will be awarded at the Canadian Association for Graduate Studies annual meeting in Toronto, Ontario, in November.

Contenders may nominate themselves or be nominated by colleagues and ex-colleagues. Nominations for a candidate must include independent testimonials from at least five researchers who have been mentored by the nominee, not all over the same period. Full details and nomination forms can be found at go.nature.com/CKbeC4.

We look forward to hearing about Canada's outstanding mentors. 